03

\title{
Влияние вязкости жидкости на формирование термокапиллярных структур
}

\author{
(C) Е.Н. Шатский ${ }^{1,2}$, Е.А. Чиннов ${ }^{1,2}$, Д.В. Зайцев ${ }^{1}$, \\ A.A. Семенов ${ }^{1,2}$, O.A. Кабов ${ }^{1,2}$ \\ ${ }^{1}$ Институт теплофизики им. С.С. Кутателадзе СО РАН, Новосибирск \\ ${ }^{2}$ Новосибирский государственный университет \\ E-mail: shatskiy.itp@gmail.com
}

\section{Поступило в Редакцию 16 мая 2017 г.}

Проведено экспериментальное исследование формирования термокапиллярных структур при малых числах Рейнольдса и градиентах температуры на поверхности пленки в широком диапазоне изменения вязкости жидкости. Выполнено обобщение данных по расстоянию между струями. Показано, что поперечный размер структур определяется капиллярной постоянной и не зависит ни от вязкости жидкости, ни от расхода (числа Рейнольдса пленки).

DOI: 10.21883/PJTF.2017.23.45278.16869

Течение тонкого слоя жидкости (пленки) по твердой поверхности относится к классу течений со свободной поверхностью, важную роль в которых играют различные механизмы неустойчивости, приводящие к развитию и взаимодействию волн различного масштаба. Пленочные течения используются в различных технологических процессах и аппаратах. Исследования теплоотдачи от плоских нагревателей к стекающей пленке жидкости начались в начале 90-х годов XX века в связи с анализом возможности использования пленочных течений для охлаждения оборудования ЭВМ.

В неизотермических пленках жидкости различают два режима образования струй [1]. В режиме $A$ на поверхности пленки в верхней части нагревателя наблюдались высокие градиенты температуры (до $10-15 \mathrm{~K} / \mathrm{mm}$ ). На поверхности нагревателя было реализовано граничное условие, близкое к $T=$ const. При достижении пороговой плотности теплового потока на поверхности пленки в верхней части нагревателя появлялись значительные деформации. Поток разделялся 
на вертикальные струи с определенной длиной волны $\lambda$. При малых числах Рейнольдса высокие термокапиллярные напряжения, направленные против потока, приводили к утолщению пленки в виде горизонтального валика [2]. Экспериментально структуры типа $A$ изучались при числе Рейнольдса $\operatorname{Re}<25$. Исследование формирования структур типа $A$ в остаточном слое волновой пленки жидкости при $\operatorname{Re}=15$ выполнено в [3], а при $\operatorname{Re}=50-$ в [4], $\operatorname{Re}=\Gamma / \rho v$, где $\Gamma-$ удельный массовый расход жидкости, $\rho-$ плотность жидкости, $v-$ коэффициент кинематической вязкости жидкости. Теоретические исследования обычно ограничиваются анализом неизотермических гладких пленок при малых числах Рейнольдса [5-8]. Было доказано существование структур А при $\operatorname{Re}<2$.

В режиме $B$ струйное течение формировалось постепенно с увеличением теплового потока и расстояния от верхнего края нагревателя [1]. На поверхности нагревателя для плотности теплового потока было реализовано граничное условие $q=$ const. Неоднородности толщины пленки поперек потока приводили к неоднородностям температуры на поверхности. Поперечный градиент температуры (до $1 \mathrm{~K} / \mathrm{mm}$ ) приводил к увеличению деформации поверхности пленки. Экспериментальное исследование эволюции гидродинамических волн в термокапиллярноволновые структуры при нагреве вертикально стекающей пленки жидкости было проведено в [9] при $\operatorname{Re}>20$. Показан факт появления температурных неоднородностей на фронте трехмерной гидродинамической волны. Из-за действия термокапиллярных сил эти неоднородности приводили к деформации пленки и образованию струй. К настоящему моменту формирование структур типа $B$ исследовалось в основном на двух жидкостях (вода и FC-72), имеющих значительно различающиеся коэффициенты поверхностного натяжения. Показано, что поверхностное натяжение оказывает существенное влияние на поперечный размер структур (расстояние между центрами струй). В работах $[10,11]$ в условиях нестационарного тепловыделения выполнены исследования теплообмена и динамики течения криогенных жидкостей. Показано, что в кризисных режимах на нагревателе формируются регулярные структуры с несмоченными зонами между ними.

В работе [12] с использованием синхронных методик измерения толщины и температуры исследуется нестационарный теплообмен в стекающих пленках жидкости. Получены локальные коэффициенты теплоотдачи. Показано, что при малой интенсивности флуктуации 
толщины пленки интенсивность флуктуации коэффициента теплоотдачи существенна, а амплитуда флуктуаций температуры на стенке почти пропорциональна амплитуде флуктуаций коэффициента теплоотдачи.

В одной из последних теоретических работ [13] подтверждено существование структур двух типов на поверхности неизотермической пленки жидкости. Показано, что в термокапиллярном режиме волновое течение пленки затухает, а в термокапиллярно-волновом режиме волны распространяются вдоль струй. Однако расчеты ограничены областью $\operatorname{Re}<5-8$ и не описывают режим гидродинамической неустойчивости волновой пленки жидкости. В работе [14] исследуется термокапиллярный разрыв пленки жидкости, стекающей под действием гравитации по вертикальной пластине с нагревателем $(150 \times 150 \mathrm{~mm})$, в широком диапазоне изменения свойств жидкости. Установлено, что вязкость жидкости оказывает существенное влияние на пороговый тепловой поток, при котором происходит разрыв пленки. Влияние вязкости жидкости на характеристики термокапиллярных структур остается неизученным, особенно в условиях малых значений чисел Рейнольдса пленки.

Задачей настоящей работы является экспериментальное исследование формирования термокапиллярных структур с градиентами температуры на поверхности пленки менее $1 \mathrm{~K} / \mathrm{mm}$ при малых числах Рейнольдса в широком диапазоне изменения вязкости жидкости.

Стенд представлял собой замкнутый циркуляционный контур, включающий резервуар с насосом, рабочий участок, фильтр, ротаметры, трубопроводы и запорную арматуру. Рабочий участок состоял из несущей плиты, на которую устанавливались пленкоформирователь, термостабилизатор и нагреватель. Рабочая жидкость с помощью насоса подавалась в пленкоформирователь, который включал накопительную камеру, распределительное устройство и сопло с калиброванной плоской щелью. Жидкость стекала по пластине и под действием гравитации возвращалась в резервуар с электронасосом. В качестве нагревательного элемента использовался электрический нагреватель шириной $150 \mathrm{~mm}$ и длиной $150 \mathrm{~mm}$. На поверхности нагревателя реализовывалось условие, близкое к $q=$ const. В эксперименте использовались следующие рабочие жидкости: вода, $60 \%$ раствор глицерина в воде, этиленгликоль. Свойства жидкостей представлены в таблице, где $\mathrm{Ka}-$ число Капицы $\mathrm{Ka}=\frac{\sigma^{3}}{g v^{4} \rho^{3}}, \mathrm{Ma}-$ число Марангони $\mathrm{Ma}=\frac{\gamma \Delta T}{\rho v^{4 / 3} g^{1 / 3}}(\sigma-$ коэффициент поверхностного натяжения, $g-$ ускорение свободного падения, $\gamma-$

Письма в ЖТФ, 2017, том 43, вып. 23 


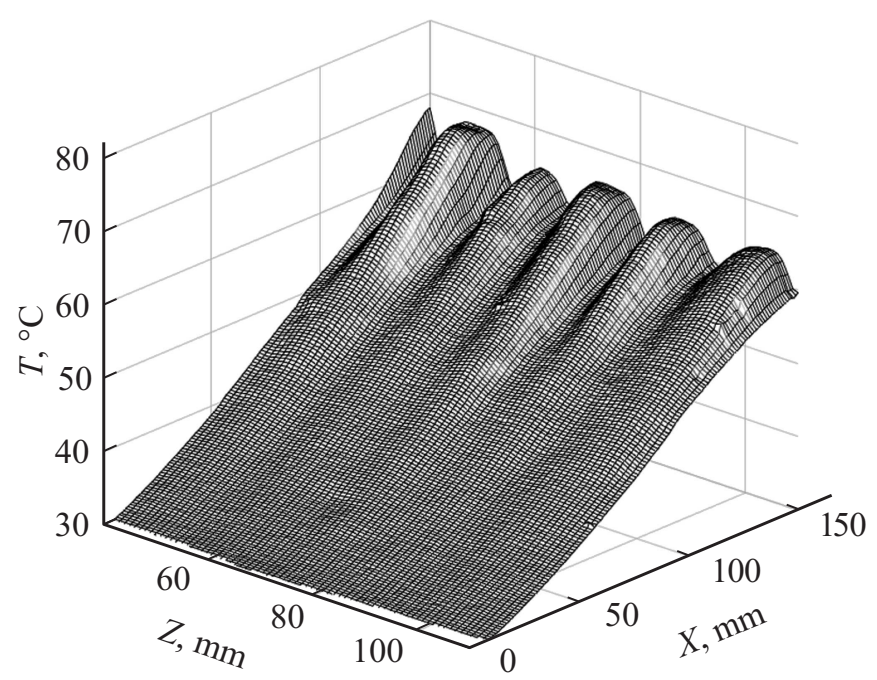

Рис. 1. Температура поверхности пленки $60 \%$ раствора глицерина в воде. $\mathrm{Re}=2, q=1.6 \mathrm{~W} / \mathrm{cm}^{2}$.

производная коэффициента поверхностного натяжения от температуры), индекс $a v$ показывает, что разница температур считается между средней температурой на поверхности пленки и начальной температурой пленки, индекс $l$ показывает, что разница температур посчитана по максимальному перепаду температур поперек течения пленки.

На рис. 1 показано распределение температуры на поверхности пленки $60 \%$ раствора глицерина в воде, где $X$ - координата, отсчитываемая от верхней кромки нагревателя, $Z-$ координата, отсчитываемая от левой кромки нагревателя. Видно, что распределение температуры вблизи верхней кромки нагревателя практически однородное. В условиях безволнового течения на поверхности пленки образуются термокапиллярные структуры в виде струй жидкости с тонкой пленкой между ними. Струи возникают на поверхности пленки постепенно с увеличением длины пробега по нагревателю. Начало формирования струй находится примерно на расстоянии $20 \mathrm{~mm}$ от верхнего края нагревателя. При этом продольные и поперечные градиенты температуры на поверхности не превышают $0.5 \mathrm{~K} / \mathrm{mm}$, разность температуры

Письма в ЖТФ, 2017, том 43, вып. 23 
Рабочие жидкости и их свойства

\begin{tabular}{l|c|c|c|c|c|c|c|c}
\hline \multicolumn{1}{c|}{ Рабочая жидкость } & $T_{0},{ }^{0} \mathrm{C}$ & $\begin{array}{c}\rho, \\
\mathrm{kg} / \mathrm{m}^{3}\end{array}$ & $\begin{array}{c}v \cdot 10^{6}, \\
\mathrm{~m}^{2} / \mathrm{s}\end{array}$ & $\begin{array}{c}\sigma \cdot 10^{3}, \\
\mathrm{~N} / \mathrm{m}\end{array}$ & $\begin{array}{c}(d \sigma / d T) \cdot 10^{3}, \\
\mathrm{~N} /(\mathrm{m} \cdot \mathrm{K})\end{array}$ & $\mathrm{Ka}$ & $\mathrm{Ma}_{a v}$ & $\mathrm{Ma}_{l}$ \\
\hline Дистиллированная вода & 24 & 997 & 0.912 & 72.16 & 0.191 & $5.6 \cdot 10^{19}$ & 59 & 11 \\
60\% раствор глицерина & 24 & 1151 & 7.665 & 67.8 & 0.131 & $6 \cdot 10^{15}$ & 3 & 2.4 \\
в воде & 24 & 1112 & 15.17 & 45.74 & 0.09 & $1.3 \cdot 10^{14}$ & - & - \\
Этиленгликоль &
\end{tabular}




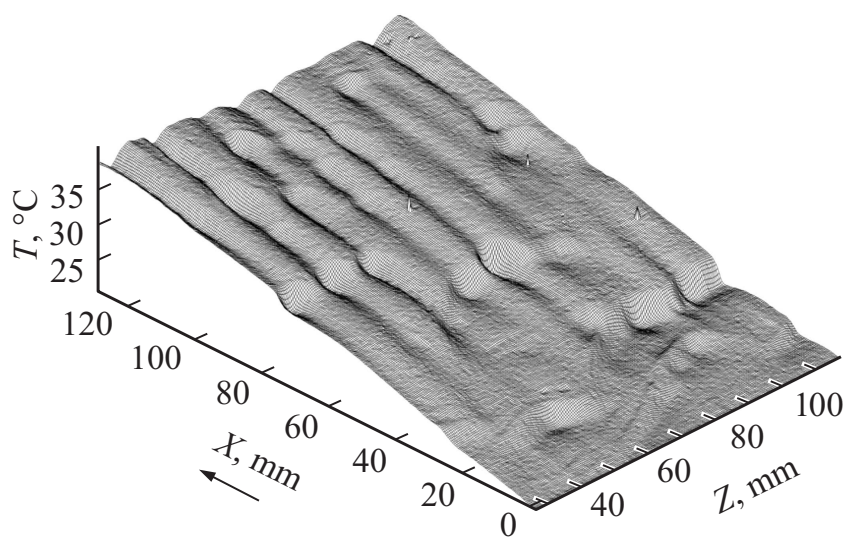

Рис. 2. Температура поверхности пленки воды. $\mathrm{Re}=10.5, q=0.88 \mathrm{~W} / \mathrm{cm}^{2}$. Стрелка показывает направление течения.

в струе и межструйной области при $X=130 \mathrm{~mm}$ имеет величину порядка $4^{0} \mathrm{C}$, а расстояние между струями составляет $14 \mathrm{~mm}$. В данных экспериментах структуры были зафиксированы и при разных значениях чисел Рейнольдса (от 0.1 до 10).

Формирование термокапиллярных структур в условиях волнообразования при $\operatorname{Re}=10.5$ представлено на рис. 2. Как видно, структуры также формировались постепенно с увеличением расстояния от верхней кромки нагревателя. Поперечные градиенты температуры на поверхности не превышают $0.5 \mathrm{~K} / \mathrm{mm}$. При движении волн на поверхности пленки возникали продольные градиенты температуры, не превышающие значения $1 \mathrm{~K} / \mathrm{mm}$. В результате воздействия термокапиллярных сил на фронт волны происходили его деформация и переход к струйному течению.

Для анализа данных были использованы разные безразмерные критерии и параметры. Обобщение всех известных данных по расстоянию между струями при формировании термокапиллярных структур типа $B$ приведено на рис. 3. Расстояния измерялись для жидкостей с различными плотностями, коэффициентами поверхностного натяжения в широких диапазонах изменения вязкости и расхода жидкости. Расстояние между струями обезразмеривалось делением на капиллярную

Письма в ЖТФ, 2017, том 43, вып. 23 


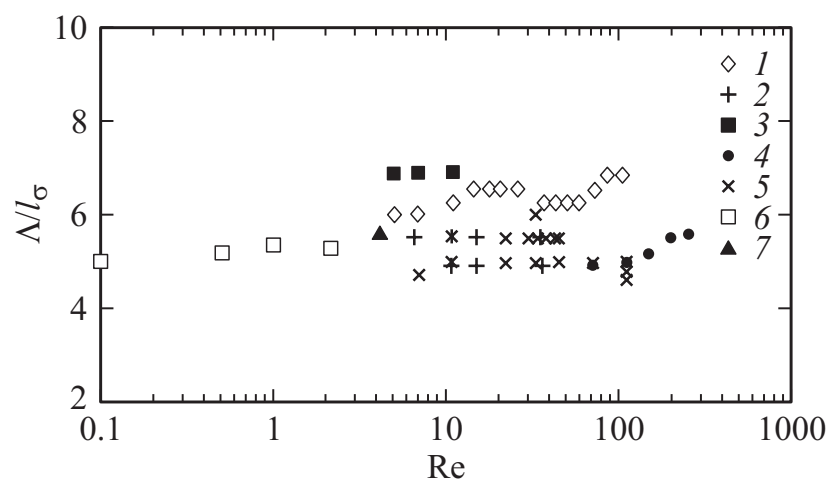

Рис. 3. Обобщение известных данных по безразмерному расстоянию между струями для структур типа $B .1-\mathrm{FC}-72$, нагреватель размером

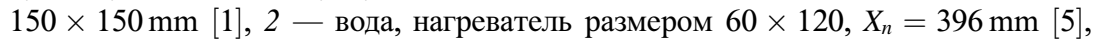
3 - FC-72, нагреватель размером $60 \times 120 \mathrm{~mm} \mathrm{[1],} 4$ - вода, нагреватель размером $100 \times 150 \mathrm{~mm}, X_{n}=263 \mathrm{~mm}, 5-$ вода, нагреватель размером $150 \times 150 \mathrm{~mm}$ (данные $[5,6]$ и настоящей работы), $6-60 \%$ раствор глицерина, нагреватель размером $150 \times 150 \mathrm{~mm}, 7$ - этиленгликоль, нагреватель размером $150 \times 150 \mathrm{~mm}$.

постоянную жидкости $l_{\sigma}=(\sigma / \rho g)^{0.5}$. Как видно, все данные по размерам структур типа $B$ попадают в диапазон от 4 до 6 и не зависят ни от вязкости жидкости, ни от числа Рейнольдса. Применение других параметров приводило к худшим результатам. Например, использование параметра $l_{\mu}=\left(\sigma \mu^{2} /\left(\rho^{3} g^{2}\right)\right)^{1 / 5}$, который применялся в [14], приводило к увеличению разброса данных на порядок.

Полученная в работе [13] теоретическая зависимость указывает на возрастание длины волны неустойчивости (расстояния между струями) с уменьшением Ма, но при этом остается неизменной тенденция ee увеличения c ростом Re, что противоречит опытным данным. При $\operatorname{Re}>5-8$ расчеты по теоретической модели [13] не приводят к формированию струйных течений, в то время как полученные опытные данные указывают на переход от трехмерного волнового течения изотермической пленки к термокапиллярно-волновому режиму $B$ при широком изменении параметров. Как следует из таблицы, диапазон изменения числа Марангони составлял почти два порядка.

Письма в ЖТФ, 2017, том 43, вып. 23 
Можно заключить, что структуры типа $B$ реализуются при относительно малых числах Марангони в условиях малых значений градиентов температуры на поверхности пленки в широких диапазонах изменения числа Рейнольдса пленки и физических свойств жидкости (числа Капицы). Поперечный размер структур (расстояние между струями) определяется капиллярной постоянной и не зависит ни от вязкости жидкости, ни от расхода (чисел Марангони, Капицы и Рейнольдса пленки).

Исследование выполнено за счет гранта Российского научного фонда (соглашение № 15-19-30038).

\section{Список литературы}

[1] Chinnov E.A., Kabov O.A. // J. Appl. Mech. Techn. Phys. 2003. V. 44. P. 708715.

[2] Kabov O.A., Marchuk I.V., Chupin V.M. // Russ. J. Eng. Thermophys. 1996. V. 6. N 2. P. $104-138$.

[3] Чиннов Е.А., Шатский Е.Н. // ТВТ. 2016. Т. 54. № 6. С. 965-968.

[4] Chinnov E.A. // Int. J. Heat Mass Transfer. 2017. V. 108. P. 2053-2059.

[5] Scheid B., Ruyer-Quil C., Manneville P. // J. Fluid Mech. 2006. V. 562. P. 183222.

[6] Kalliadasis S., Kiyashko A., Demekhin E.A. // J. Fluid Mech. 2003. V. 475. P. 377-408.

[7] Frank A.M., Kabov O.A. // Phys. Fluids. 2006. V. 18. № 3. P. 032107.

[8] Dávalos Orozco L.A. // Interfacial Phenom. Heat Transfer. 2013. V. 1/2. P. 93138.

[9] Чиннов Е.А., Назаров А.Д., Сапрыкина А.В., Жуковская О.В., Серов А.Ф. // TBT. 2007. T. 45. № 5. С. 725-732.

[10] Чернявский А.Н., Павленко А.Н. // Письма в ЖТФ. 2014. Т. 40. В. 23. С. 1-8.

[11] Павленко А.Н., Суртаев А.С., Мацех А.M. // ТВТ. 2007. Т. 45. N 6. C. $905-$ 916.

[12] Markides S.N., Mathie R., Charogiannis A. // Int. J. Heat Mass Transfer. 2016. V. 93. P. $872-888$.

[13] Scheid B., Kalliadasis S., Ruyer-Quil C., Colinet P. // Phys. Rev. E. 2008. V. 78. P. 066311.

[14] Зайцев Д.В., Семенов А.А., Кабов О.А. // Теплофизика и аэромеханика. 2016. Т. 23. № 4. С. 649-652. 